\title{
5D Building Information Modelling - A Practicability Review
}

\author{
Xia Sheng Lee ${ }^{1, a}$, Cheah Wei Tsong ${ }^{2}$ and Mohd Faris Khamidi ${ }^{1}$ \\ ${ }^{1}$ School of the Built Environment, University of Reading Malaysia, Persiaran Graduan, Kota IImu, Educity, 79200 Nusajaya, Johor, Malaysia. \\ ${ }^{2}$ Universiti Tunku Abdul Rahman, Jalan Sungai Long, Bandar Sungai Long, Cheras, 43000, Kajang, Selangor, Malaysia.
}

\begin{abstract}
Quality, time and cost are the three most important elements in any construction project. Building information that comes timely and accurately in multiple dimensions will facilitate a refined decision making process which can improve the construction quality, time and cost. 5 dimensional Building Information Modelling or 5D BIM is an emerging trend in the construction industry that integrates all the major information starting from the initial design to the final construction stage. After that, the integrated information is arranged and communicated through Virtual Design and Construction (VDC). This research is to gauge the practicability of 5D BIM with an action research type pilot study by the means of hands-on modelling of a conceptual bungalow design based on one of the most popular BIM tools. A bungalow is selected as a study subject to simulate the major stages of 5D BIM digital workflow. The whole process starts with developing drawings (2D) into digital model (3D), and is followed by the incorporation of time (4D) and cost (5D). Observations are focused on the major factors that will affect the practicability of 5D BIM, including the modelling effort, inter-operability, information output and limitations. This research concludes that 5D BIM certainly has high level practicability which further differentiates BIM from Computer Aided Design (CAD). The integration of information not only enhanced the efficiency and accuracy of process in all stages, but also enabled decision makers to have a sophisticated interpretation of information which is almost impossible with the conventional 2D CAD workflow. Although it is possible to incorporate more than 5 dimensions of information, it is foreseeable that excessive information may escalate the complexity unfavourably for BIM implementation. 5D BIM has achieved a significant level of practicability; further research should be conducted to streamline implementation. Once 5D BIM is matured and widely accepted, it is foreseeable that additional BIM dimensions of information will be incorporated into sophisticated digital building model to achieve specific project outcomes.
\end{abstract}

\section{Introduction}

A construction project's success is influenced by the management of quality, time and cost. The major things that concern construction project clients, but are not limited to value for money, include : pleasing to look at, free from defects on completion, delivery on time, fit for the purpose, supported by worthwhile guarantees, reasonable running costs, and satisfactory durability [1]. However, the information generated in a construction project is huge and sometimes inconsistent. This will increase the difficulty of project planning which may lead to misinterpretations and misunderstandings related to project results [2]. The construction project clients, ranging from an owner of a house to a big company having their corporate headquarters, will be at the receiving end of uncertain outcomes for one of their biggest investments. If this uncertainty is not mitigated, it will affect the construction industry's adaptability in a rapidly changing society. All in all, stakeholders have been disadvantaged by the fragmented nature of construction process for way too long, until the development of Building information modelling (BIM) in recent years.

The popular interpretation of BIM is about a new approach to design, construction, and facility Management [3]. BIM is also viewed as a tool to improve architectural practice moving from a computer aided design (CAD). Therefore, there are research that has been conducted exploring the integration of various dimensions of information into 5 dimensional (5D) BIM for better project outcome [4]. The 5D BIM approach is a brave attempt on transforming the whole construction process. However, a lot of stakeholders including professionals in the construction industry still do not understand the practicability aspects of 5D BIM. Major misconceptions among stakeholders often fall into the extremes either viewing it as a straightforward "solution to all" or merely an overrated improvised Computer Aided Design (CAD). Therefore, this research will focus on subjects that influence the practicability of 5D BIM, inclusive of modelling effort, inter-operability, information output and limitations, with a hands-on approach.

\footnotetext{
a Corresponding author: x.s.lee@reading.edu.my, leexiasheng@gmail.com
} 


\subsection{Building Information Modelling}

BIM is instrumental in shifting the construction industry's paradigm from two dimensional (2D) based drawing information systems to a three dimensional (3D) object information systems [5]. This transformation changes the documentation method used in building design and construction, from manual conducts which are human readable [6], and integrates digital descriptions of building elements with other information [7] including time and cost which are computer readable. This process is recognised as n-dimensional (n-D) modelling, where different "dimensions" of information are integrated into a digital building model [8]. Consequently, the BIM framework is developed to define deliverables for construction industry stakeholders and to achieve Integrated Project Delivery (IPD) [9].

\subsection{Time as 4D in Building Information Modelling}

Time is a very unique non-material element in construction projects that can be presented in various perspectives including time-space conflicts [10] and construction schedule visualization [11]. Attempts at incorporating time as additional information to evaluate and analyse different kinds of project sequences comes in the form of 4D Computer Aided Design (CAD) [12]. These earlier researches are the fundamentals of 4D BIM towards construction progress measurement [13]. Time is logically prioritized over cost as $4 \mathrm{D}$ in BIM, due to the fact that the cost may fluctuate over time. However, it is obvious that $4 \mathrm{D}$ BIM is not complete and should be complimented with cost as $5 \mathrm{D}$ to achieve better project outcome.

\subsection{Cost as 5D in Building Information Modelling}

The importance of accuracy in cost estimation during the early stages of construction projects has been widely recognized. In the past, cost estimation for construction materials based on user's experience was essential because the cost estimation is the prediction of cost for a process or project using experience or methodology [14]. Cost estimation is very significant for decision making [15] as inaccurate estimation may lead to disastrous cost overrun and project delay [16]. Early project estimation represents a major factor in business unit decisions and often becomes the basis for a project's ultimate funding [17]. In spite of great importance given to cost estimation, it is neither simple nor straightforward due to deficiency of information in the early stages of the project [18]. Such gap in information can be bridged by 5D BIM [19] for better project financing and cash flow control [20]. Integration framework of cost and schedule [21] was developed a few years back and is presently under rapid advancement.

\subsection{Practicable 5D Building Information Modelling Through Virtualisation}

Construction project data such as time and cost in the isolated form without integration often carry little meaning. Integration of cost and schedule framework shaped schedule and cost management systems [21] and repetitive construction processes [22]. 5D BIM which combine building information model (3D), time (4D) and cost (5D) is aligned with such framework, integrating the isolated data into smart information useful for various purposes. 5D BIM in the form of multi-disciplinary performance models can be further utilised through Virtual Design and Construction (VDC), defined as the use of design-construction projects [23] to support explicit and business objectives. Project VDC usually emphasizes those aspects of the project that can be designed and managed, so that the team will be able to define, design, construct and operate the models [24]. Such performance models can accurately relate the predicted performance in relationship to the actual project result [25].

The virtualisation of BIM can improve the quality of information sharing, comparison and project integration by the stakeholders. As construction progresses, VDC can make consistency and accuracy checking for different dimensions of information such as building element's sizes and materials in an intuitive way [7]. VDC will also able to provide a graphical coordination of the design, operation and construction of the building including its fabrication and assembly details [26]. The process involves using BIM software that allows building information model to be presented by combining building components (3D), time scheduling (4D) and cost estimation (5D) [27].

\section{Methodology}

This is an action research type pilot study [28] with no collection of hard data, but with outputs, including model drawings, scheduling and time liner that are produced for examination. The action research pilot study outputs are later followed by expert reviews [29]. A sample bungalow is used as reference for this pilot study. The research methodology is to simulate and analyse the whole 5D BIM focusing on modelling effort, interoperability, information output and limitation with a hands-on approach which are divided into 4 stages as shown in Figure 1. Observations are captured with the purpose to gauge the practicability of 5D BIM.

The first stage involves the collection and input of building information into 3D model. This process starts with clients briefing on their requirements that lead to an initial proposal. Architectural proposal is formed and the $3 \mathrm{D}$ model is then created by incorporating other disciplines such as civil and structural engineering, mechanical and electrical engineering and interior design. The 3D model contains information that specifies each and every component.

The second stage will take place after clients are satisfied with the initial design that comply to the specified requirements. Quantity surveyors or cost engineers will input the information for cost estimation into the $3 \mathrm{D}$ model. The cost estimation is done by 
automating quantification of building elements with unit price. At this stage, 4D BIM is very useful to assist clients in refining their priorities from the perspective of cost estimation.

The third stage will proceed when the clients are satisfied with the concluding 4D BIM. Project managers will create Work Breakdown Structure (WBS) for all types of construction activities. Since the integration is done with BIM, it can cater for a huge amount of information, with WBS containing more levels compared to a conventional system. Some of the critical factors such as construction method, human resources, material procurement and supply will affect the project time scheduling. At this stage, all the necessary information is integrated as 5D BIM. In the final stage, VDC will be implemented to present 5D BIM project components, project cost and time scheduling.

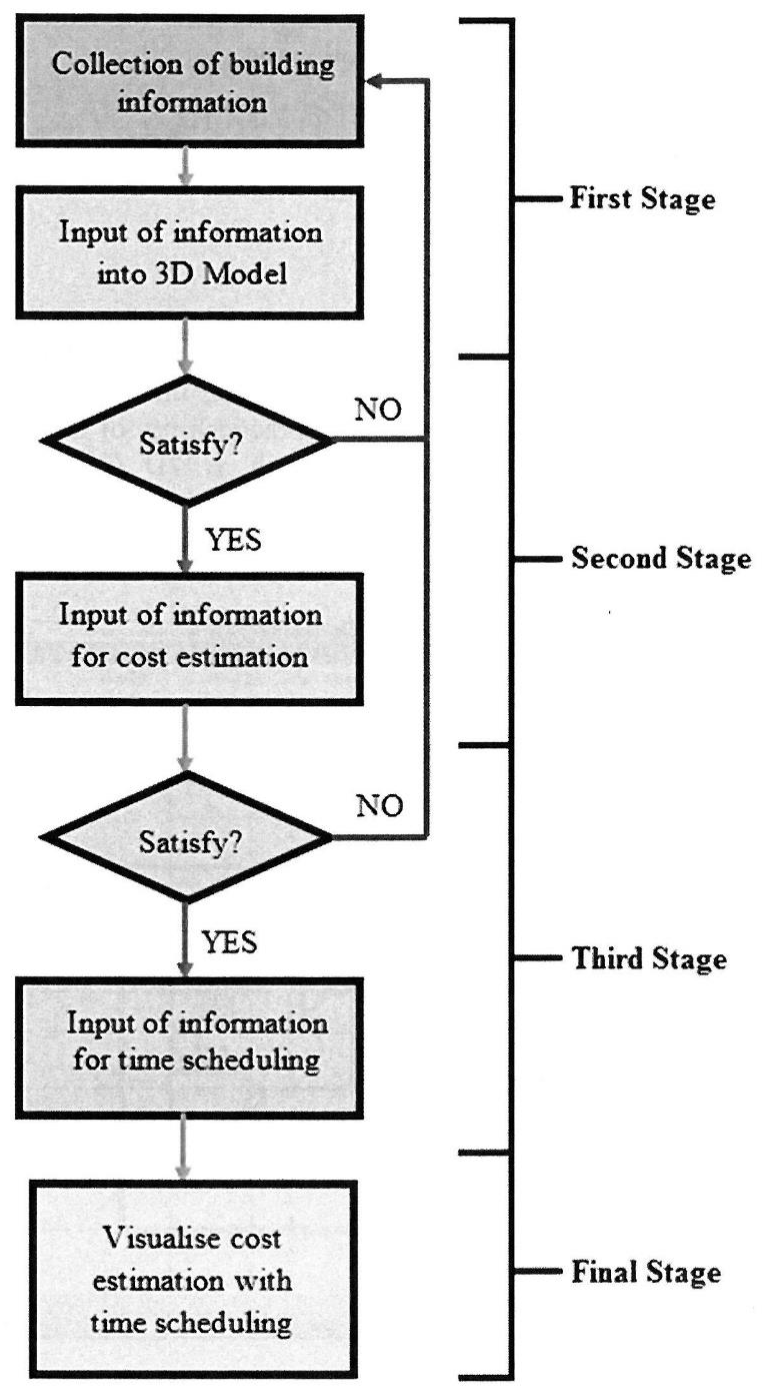

Figure 1. 5D BIM Process Flowchart.

\subsection{Apparatus}

There are different types of BIM software available in the market. One of the widely used softwares is Autodesk Revit. Some of the strengths of Autodesk Revit include automation [30] and it communicates better to the stakeholders [31]. The main factor for Autodesk Revit being chosen as the modelling tool in this research is because this software is decent in multidisciplinary integration and configurable automation, which is significant for 5D BIM workflow. The modelling tools and content are limited only to Revit Architecture and Revit Structure. The VDC tool chosen for this research is Autodesk Navisworks Manage, to have a seamless simulation process. The hardware setting up follows system requirements for Autodesk Revit 2016: Value: Balanced price and performance category as the following:

\section{- CPU Type : Quad-Core Intel i5-4590S CPU @ $3.00 \mathrm{GHz}$ \\ - Memory $: 8$ GB RAM \\ - Video Display : 1,680 x 1,050 with true colour \\ - Disk Space : 5 GB free disk space}

\subsection{Collection and Input of Building Information into 3D Model}

The practicability of BIM will be affected by competency in integrating pre-BIM information such as 2D CAD information. Although BIM has gained popularity over the years, there are stakeholders who are still relatively new to this new approach. Therefore, preliminary information in the form of $2 \mathrm{D}$ drawings needs to be analysed in order to locate major grid lines and border lines. Figure 2, shows the grid lines of the bungalow unit that is essential to set up components such as columns, slabs, beams and walls.

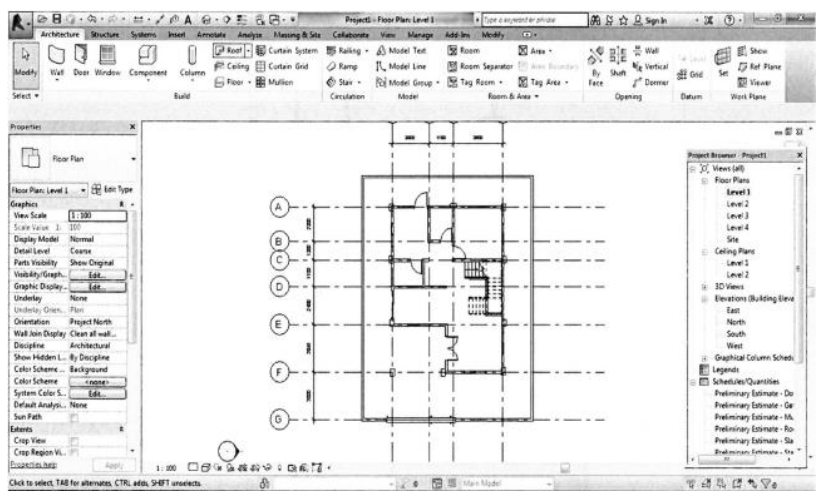

Figure 2. Level 1 floor plan for conceptual bungalow design.

\subsection{Input of Information for Cost Estimation}

Sattineni and Bradford (2011) agree that BIM is actually one of the best automatic approaches to directly generate an accurate quantity take off from $3 \mathrm{D}$ product models [32]. Cost estimation will require automated information extraction of various properties such as 'Family and Type' and 'Volume' of the components. After that, quantity surveyors or cost engineers will have to input the components' information of per unit 'Cost'. The information of per unit 'Cost' is then linked through formula or percentage computation as shown in Figure 3 with 'Family and Type' and 'Volume' of the 
components. Figure 4, shows an example of the complete schedule of properties with cost estimation.

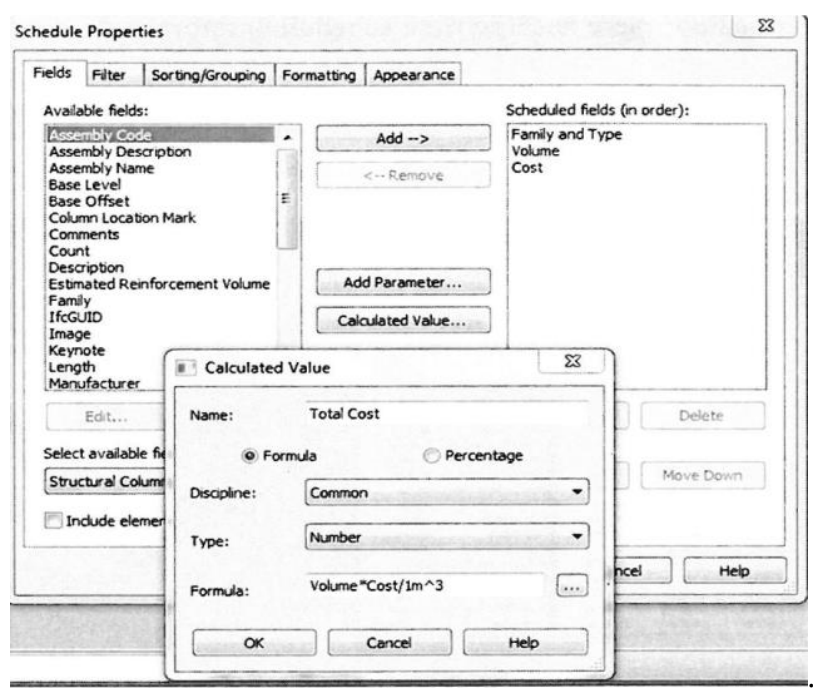

Figure 3. Cost estimation with formula.

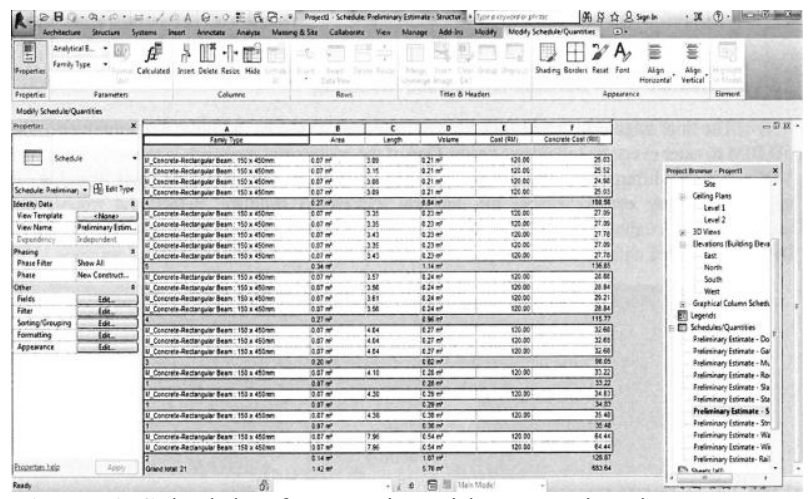

Figure 4. Schedule of properties with cost estimation.

\subsection{Input of Information for Time Scheduling}

Similar to 2D CAD, project management with time scheduling is conventionally done by utilising software like Microsoft Project, Primavera or Excel. Such information of time scheduling has to be linked to each and every component according to the specific WBS. Similar to 2D CAD information, these specific time scheduling information are interchangeable with BIM software such as Autodesk Naviswork Manage, as shown in Figure 5.

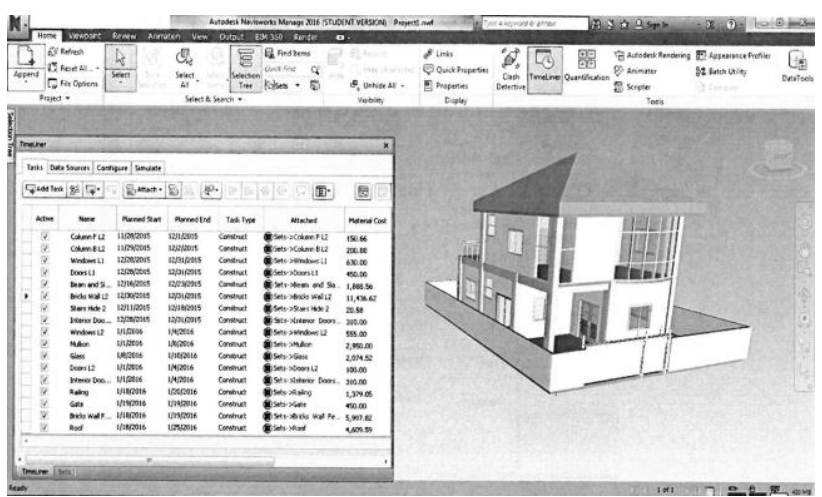

Figure 5. 5D Building Information Modelling.

\subsection{Virtualisation of 5D Building Information Modelling}

The final stage is to create animation or time liner as shown in Figure 6 to intuitively present 5D BIM, catering to every stakeholder's needs. One of the resourceful approaches is to create comparative VDCs that are different in construction methods, human resource planning, cost planning. This approach is very comprehensive for clients and decision makers to simulate, detect and trouble shoot uncertainties throughout the whole construction project. As the construction progresses, 5D BIM as-built information virtualisation should be done to monitor between the plan and actual progress.

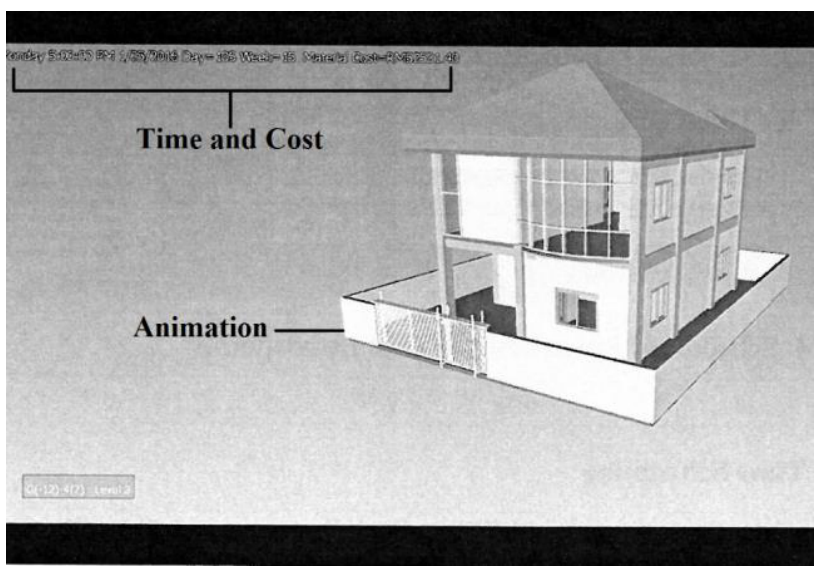

Figure 6. Time liner for 5D Building Information Modelling.

\section{Practicability of 5D Building Information Modelling}

5D BIM is the systematic integration between 3D model, time and cost as shown in Figure 7. The integration success will be heavily influenced by modelling effort, inter-operability, information output and limitation. 


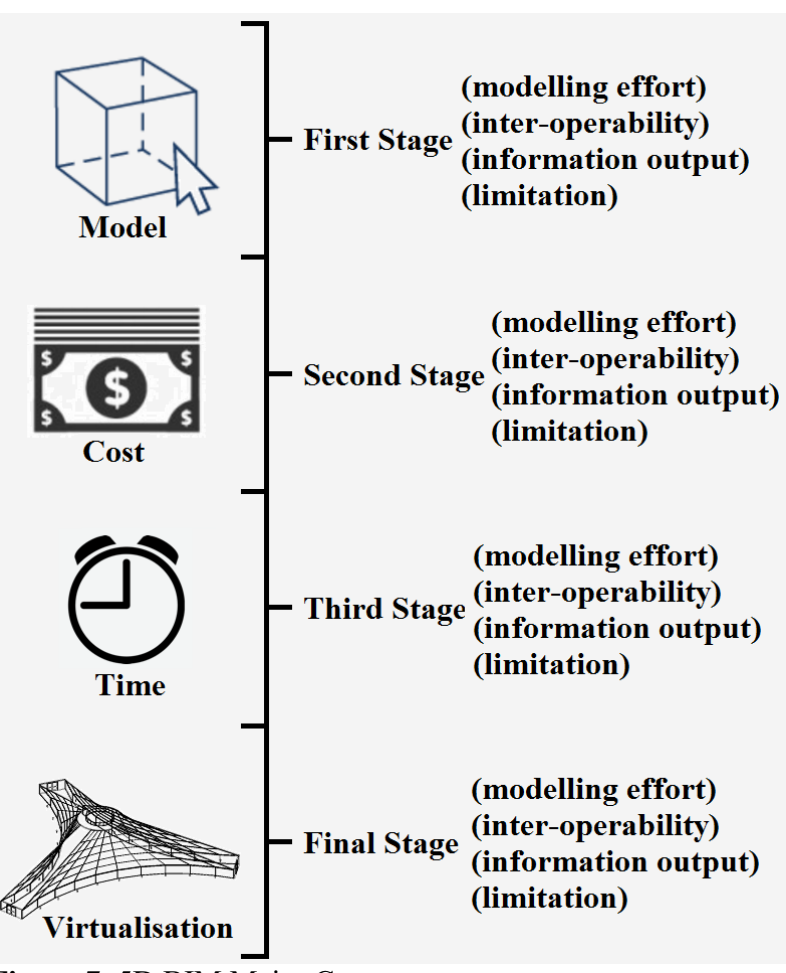

Figure 7. 5D BIM Major Components

The research is conducted by researchers and professionals who have experience with the conventional 2D CAD construction industry workflow. Therefore, the practicability of 5D BIM can be gauged directly, compared to the conventional 2D CAD workflow.

The first stage simulation discovers that the effort of modelling depends highly on the modeller's skill level. This is similar to CAD; thus it is considered neutral. Inter-operability is considered poor due to different modelling tools being based on unique systems and engines that are competing against one another. The information output is very compressive; thus, considered good when compared to CAD.

The second stage is about input of information for cost estimation where the effort is easy by computing simple formulas. BIM's inter-operability is considered neutral when compared to $\mathrm{CAD}$, but the information outputs are very fast and accurate.

The third stage simulates time scheduling in 3D model which cannot be compared directly with 2D CAD workflow. Therefore, the modelling effort is considered neutral. Unlike the first stage, collaboration that involves completed building information model is easy due to high inter-operability. The information output is good as nonprofessional stakeholders are empowered to easily understand 5D BIM.

The final stage involves virtualisation where the effort highly depends on existing 5D BIM quality. It is considered as neutral in the pilot study; however, the advancement of technology certainly will reduce the modelling effort. Both inter-operability and information output are good, as this stage is usually directly linked to clients or end users.

These qualitative observations are summarised in Table 1 as a pilot study.
Table 1. Observation on 5 D Building Information Modelling practicability

\begin{tabular}{|c|c|c|c|}
\hline Stage & Process & Criteria & Observation \\
\hline \multirow[b]{4}{*}{1} & \multirow{4}{*}{$\begin{array}{l}\text { Collection and } \\
\text { Input of } \\
\text { Building } \\
\text { Information } \\
\text { into 3D Model }\end{array}$} & modelling effort & neutral \\
\hline & & inter-operability & poor \\
\hline & & $\begin{array}{l}\text { information } \\
\text { output }\end{array}$ & good \\
\hline & & limitation & $\begin{array}{l}\text { Non BIM- } \\
\text { capable } \\
\text { stakeholders } \\
\text { will face } \\
\text { obstacles to } \\
\text { proceed to } \\
\text { stage } 2 .\end{array}$ \\
\hline \multirow[b]{4}{*}{2} & \multirow{4}{*}{$\begin{array}{l}\text { Input of } \\
\text { Information for } \\
\text { Cost } \\
\text { Estimation }\end{array}$} & modelling effort & good \\
\hline & & inter-operability & neutral \\
\hline & & $\begin{array}{l}\text { information } \\
\text { output }\end{array}$ & good \\
\hline & & limitation & $\begin{array}{l}\text { Cost } \\
\text { information } \\
\text { cannot be } \\
\text { automatically } \\
\text { updated by } \\
\text { suppliers. }\end{array}$ \\
\hline \multirow[b]{4}{*}{3} & \multirow{4}{*}{$\begin{array}{l}\text { Input of } \\
\text { Information for } \\
\text { Time } \\
\text { Scheduling }\end{array}$} & modelling effort & neutral \\
\hline & & inter-operability & good \\
\hline & & $\begin{array}{l}\text { information } \\
\text { output }\end{array}$ & good \\
\hline & & limitation & $\begin{array}{l}\text { Requires site } \\
\text { knowledge } \\
\text { and localized } \\
\text { experience to } \\
\text { have realistic } \\
\text { output. }\end{array}$ \\
\hline \multirow[b]{4}{*}{4} & \multirow{4}{*}{$\begin{array}{l}\text { Virtualisation } \\
\text { of 5D Building } \\
\text { Information } \\
\text { Modelling }\end{array}$} & modelling effort & neutral \\
\hline & & inter-operability & good \\
\hline & & $\begin{array}{l}\text { information } \\
\text { output }\end{array}$ & good \\
\hline & & limitation & $\begin{array}{l}\text { Modelling } \\
\text { process still } \\
\text { difficult when } \\
\text { handling large } \\
\text { amount of } \\
\text { information. }\end{array}$ \\
\hline
\end{tabular}

\section{Conclusion}

BIM is an emerging approach that is currently transforming the construction industry. Although it is possible to incorporate more than 5 dimensions of information, it is foreseeable that excessive information may escalate the complexity unfavourably for BIM implementation. Therefore, qualitative exploration is done in this research to gauge the next benchmark which is 5D BIM. Observations clearly indicate a significant level of practicability on all 4 major stages of 5D BIM. The integration of information not only enhanced the efficiency and accuracy of process in all stages, but also enabled decision makers to have a sophisticated interpretation of information which is almost impossible with the conventional 2D CAD workflow. However, 
observation also indicates that non BIM-capable stakeholders will have limitations to participate and benefit from 5D BIM. Therefore, non-BIM capable stakeholders should be committed to build their BIM capability benchmarking on the 5D BIM workflow. Virtualisation of 5D Building Information Modelling will significantly reduce technical barriers for clients to participate in the project. This will increase clients' satisfaction by bridging the gap of expectation and actual project outcomes. All in all, more research should be focused on the development of practical 5D BIM best practises.

\section{References}

1. M. Latham. The Latham Report.: Constructing the Team. (1994)

2. L. Kestle. Remote Site Design Management (2009)

3. C. Eastman, P. Teicholz, R. Sacks, K. Liston. BIM Handbook: A Guide To Building Information Modeling For Owners, Managers, Designers, Engineers \& Contractors. John Wiley \& Sons, NJ. (2011)

4. V. Popov, V. Juocevicius, D. Migilinskas, L. Ustinovichius, S. Mikalauskas. The use of a Virtual Building Design \& Construction Model for Developing an Effective Project Concept in 5D Environment. Automat. Constr., 19, 357 (2010)

5. S. Mihindu, Y. Arayici. Digital Construction through BIM System will Drive the Reengineering of Construction Business Practices. Int. Conf. Visualisation, 29 (2008)

6. D. K. Smith, M. Tardif, BIM: A Strategic Implementation Guide for Architects, Engineers, Constructors and Real Estate Asset Managers. John Wiley \& Sons, NJ. (2009)

7. C. Egbu, B. Sidawi. Building Information Modelling Implementation and Remote Construction Project Issues, Challenges, and Critiques. J. ITcon, 12, 75 (2012)

8. M. Kagioglou. Developing a vision of $n D$-enabled construction. (2003)

9. B. Succar. Building Information Modelling framework: A research \& delivery foundation for industry stakeholders. Automat. Constr., 18, 357 (2009)

10. B. Akinci, M. Fischer, R.E. Levitt, R. Carlson. Formalization and Automation of Time-Space. CA. J. Comput. Civil Eng., 16,124, (2002)

11. K. W. Chau, M. Anson, J. P. Zhang. Four Dimensional visualization of construction scheduling and site utilization. J. Constr. Eng. M., 130, 598 (2004)

12. D. Heesom, L. Mahdjoubi. Trends of $4 D C A D$ application for construction planning. Constr. M. Econ, 22, 171 (2004)

13. C. Kim, H. Son, C. Kim. Automated construction progress measurement using a 4D Building
Information Model and 3D data. Automat. Constr., 31, 75 (2013)

14. S. Perera, I. Watson. Collaborative Case-Base Estimating and Design. J. Adv. in Eng., 29, 801-8 (1998)

15. R. Carr. Cost Estimating Principles. J. Constr. Eng. M., 115, 545. (1989)

16. P. F. Kaming, P. O. Olomolaiye, G. D. Holt, F. C. Harris. Factors of Influencing Construction Time and Cost Overruns on High-Rise Project in Indonesia. J. Constr. M. Econ., 15 (2010)

17. S. Trost, G. Oberlender. Predicting Accuracy of Early Cost Estimate Using Factor Analysis and Multivariate Regression. J. Constr. Eng. M., 129, 198 (2003)

18. T. Hegazy, Computer-Based Construction Project Management. Prentice- Hall Inc., New Jersey. (2002)

19. D. Forgues, I. Iordanova, F. Valdivesio, S. StaubFrench. Rethinking the cost estimating process through 5D BIM: a case study. In Constr. Res. Congress, 778 (2012)

20. H. Liu, M. Lu, M. Al-Hussein. BIM-Based Integrated Framework for Detailed Cost Estimation and Schedule Planning of Construction Project. (2014)

21. K. Cho, T. Hong, C. Hyun. Integrated Schedule and Cost Model for Repetitive Construction Process. J. M. Eng., 26, 78 (2010)

22. D. Cho, J. S. Russell, J. Choi. Database Framework for Cost, Schedule, and Performance Data Integration. J. Compu. Civil Eng., 27, 719 (2013)

23. M. Fischer, T. Hartmann, E. Ranks, F. Neuberg. Combining Different Project Modelling Approaches for Effective Support of Multi-Disciplinary Engineering Tasks. World IT Constr. Conf., 167 (2004)

24. B. Gilligan, J. Kunz. V.D.C. use in 2007 Significant Value, Dramatic Growth and Apparent Business Opportunity. Center for Integrated Facility Engineering Report, Stanford University. (2007)

25. J. Kunz, M. Fischer. V.D.C.: Themes, Case Studies and Implementation Suggestions. Center for Integrated Facility Engineering Report, Stanford University. (2012)

26. R. L. Solnosky. Integrated Structural Process Model: AN Inclusive Non-Material Specfic Approach to Determining the Required Tasks and Information Exchanges for Structural Building Information Modelling. The Pennsylvania State University, Pennsylvania. (2013)

27. B. Hardin, D. McCool. BIM and Construction Management: Proven Tools, Methods and Workflows. John Wiley and Sons Inc., Indiana. (2015)

28. J. Scorgie, J. Whyte. Using Laser Scans to Visualize and Make Decisions about Built Infrastructure. DIRC Working Paper 7, version 1.0. (2013)

29. R. L. Mack, J. Nielsen, Usability inspection methods. Wiley, New Jersey. (1994)

30. L. Khemlani. Autodesk Revit: Implementation in Practice. White paper, Autodesk. (2004) 
31. T. Olofsson, G. Lee, C. Eastman. Benefits and Lessons Learned of Implementation Building Virtual Design, and Construction (VDC) Technologies for Coordination of Mechanical, Electrical and Plumbing (MEP) Systems on A Large Healthcare Project. J. ITcon, 13, 324 (2008)

32. A. Sattineni, R. H. Bradford. Estimating with BIM: A Survey of US Construction Companies. Proceedings of the 28th ISARC, 564-569. (2011) 